\title{
MiR-182-5p protects inner ear hair cells from cisplatin-induced apoptosis by inhibiting FOXO3a
}

\author{
Yimeng $\mathrm{Li}^{1,2}$, Ao $\mathrm{Li}^{1,2}$, Jingfang $\mathrm{Wu}^{1,2}$, Yingzi $\mathrm{He}^{2,3}$, Huiqian $\mathrm{Yu}^{1,2}$, Renjie Chai ${ }^{4,5}$ and Huawei $\mathrm{Li}^{\star *, 1,2,6,7}$
}

Cisplatin is widely used for chemotherapy of a variety of malignancies. However, the clinical application of cisplatin is hampered by the resultant irreversible hearing loss due to hair cell apoptosis. To date, no practical regimen to resolve this has been developed. Meanwhile, the role of microRNA in protecting hair cells from cisplatin-induced apoptosis in the inner ear has not been extensively investigated. In this study, we monitored miR-183, -96 , and -182 turnover in the cochlea during cisplatin treatment in vitro. We found that overexpression of miR-182, but not miR-183 and -96 , improved hair cell survival after $3 \mu \mathrm{M}$ cisplatin treatment in vitro. We demonstrated that overexpression of miR-182 repressed the intrinsic apoptotic pathway by inhibiting the translation of FOXO3a. Our study offers a new therapeutic target for alleviating cisplatin-induced hair cell apoptosis in a rapid and tissue-specific manner. Cell Death and Disease (2016) 7, e2362; doi:10.1038/cddis.2016.246; published online 8 September 2016

As the cornerstone of platinum-based chemotherapy regimens, cisplatin (cis-diamminedichloroplatinum-II; DDP) is widely used as the first-line treatment of a variety of malignancies, including lung and ovarian cancers and lymphoma. ${ }^{1,2}$ The application of cisplatin significantly improves patient survival rates, whether as adjuvant treatment combined with surgery or salvage treatment for unresectable disease.$^{3,4}$ However, the use of cisplatin is severely limited by its unwanted side effects, including ototoxicity and nephrotoxicity, which reduce patient tolerance during treatment and interfere with the long-term quality of life. ${ }^{5,6}$ The cytotoxicity of cisplatin is mediated by induction of apoptosis. ${ }^{7,8}$

In the inner ear, cisplatin leads to irreversible hair cell loss, together with damage to both the spiral ganglion and stria vascularis. ${ }^{6,9,10}$ The mechanism of cisplatin-induced apoptosis is unclear. ${ }^{2}$ The most frequently used strategy to relieve cisplatin-induced ototoxicity is the use of antioxidants and anti-inflammatory agents. ${ }^{11,12}$ However, the treatments mentioned above have remained at the pre-clinical stage due to their limited curative effects or at the undesirable expense of tumoricidal efficacy. Therefore, further understanding of cisplatin-induced apoptosis is necessary for the development of new strategies to protect hair cells.

MicroRNAs (miRNAs) are a class of endogenous non-coding RNAs 20-22 nucleotides in length. They negatively regulate gene expression at the post-transcriptional level by binding to partially complementary sites in the 3'-untranslated regions (3'UTR) of target messenger RNAs (mRNAs). miRNAs have important roles in regulating many biological processes, such as proliferation, differentiation, and cell death. ${ }^{13,14}$ In vertebrates, the expression of the highly conserved miR-183/96/182 cluster (hereafter, miR-183/96/182) is predominant in ciliated sensory organs. ${ }^{15,16}$ In the inner ear, their expression is confined to hair cells and the spiral ganglion. ${ }^{17,18}$ Previous studies have revealed the importance of miR-183-5p, -96-5p, and -182-5p (hereafter, miR-183, -96, and -182) in hair cell development and maintenance..$^{1,20}$ Other studies conducted in cancer cells have reported their anti-apoptotic effects. ${ }^{21,22}$ However, the roles of miR-183, -96 , and -182 in protecting hair cells from cisplatininduced apoptosis have not been investigated.

In this study, we monitored the kinetic changes in miR-183, -96 , and -182 levels during cisplatin treatment in organ of Corti explants. MiR-182 overexpression had a protective effect against cisplatin-induced hair cell apoptosis in vitro. Furthermore, miR-182 overexpression inhibited the expression of FOXO3a in hair cell nuclei. We also identified a direct interaction between miR-182 and FOXO3a by immunoprecipitation assay. Therefore, miR-182 might protect inner ear hair cells from cisplatin-induced apoptosis through inhibition of $\mathrm{FOXO} 3$.

\section{Results}

Rapid turnover of miR-183, -96 , and $\mathbf{- 1 8 2}$ under cisplatin treatment. First, we investigated the extent of hair cell loss according to cisplatin concentration. Organ of Corti explants were cultured in medium containing 3,20 , or $30 \mu \mathrm{M}$ cisplatin for $24 \mathrm{~h}$. Hair cells were counted at 0,24 , and $48 \mathrm{~h}$ after cisplatin

\footnotetext{
${ }^{1}$ Department of Otorhinolaryngology, Affiliated Eye and ENT Hospital of Fudan University, Shanghai 200031, China; ${ }^{2}$ Key Laboratory for Hearing Science, Ministry of Health, Affiliated Eye and ENT Hospital of Fudan University, Shanghai 200031, China; ${ }^{3}$ Central Laboratory, Affiliated Eye and ENT Hospital of Fudan University, Shanghai 200031. China; ${ }^{4}$ Key Laboratory for Developmental Genes and Human Disease, Ministry of Education, Institute of Life Sciences, Southeast University, Nanjing 210096, China; ${ }^{5} \mathrm{Co}$-innovation Center of Neuroregeneration, Nantong University, Nantong 226001, China; ${ }^{6}$ Institutes of Biomedical Sciences, Fudan University, Shanghai 200032, China and ${ }^{7}$ State Key Laboratory of Medical Neurobiology, Fudan University, Shanghai, China

${ }^{*}$ Corresponding author: Huawei Li, Department of Otorhinolaryngology, Affiliated Eye and ENT Hospital of Fudan University, No.83 Fenyang Road, Shanghai, 200031 , P.R. China; Tel: 86-21-64377134-669; Fax: +86 21 64377151; E-mail: hwli@shmu.edu.cn

Abbreviations: DDP, cisplatin, cis-diamminedichloroplatinum-II; 3'-UTR, 3'-untranslated regions; FOXO, forkhead box transcription factor; z-VAD-fmk, z-Val-Ala-Aspfluoromethylketone; Bax, BCL2-associated X protein; Apaf-1, apoptotic peptidase activating factor 1; FADD, FAS-associated protein with a death domain; TMRE, tetramethylrhodamine ethyl ester; BRCA1, breast cancer type 1 susceptibility protein; RISCs, RNA-induced silencing complexes; Ago2, Argonaute 2; RIP, RNA-binding protein immunoprecipitation

Received 17.12.15; revised 14.6.16; accepted 13.7.16; Edited by A Oberst
} 

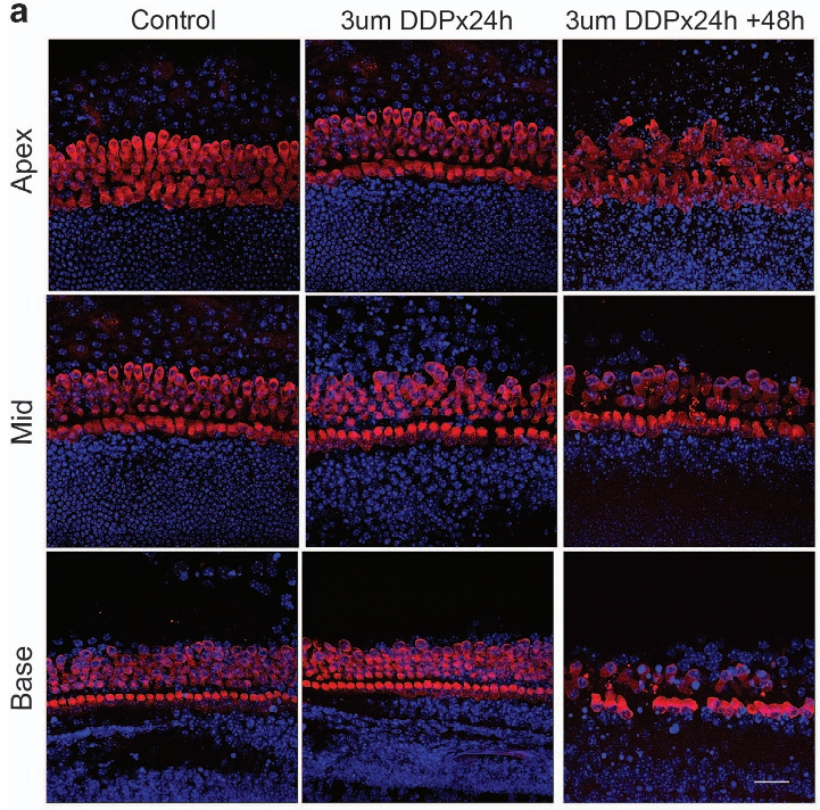

Myosin 7a / DAPI

b

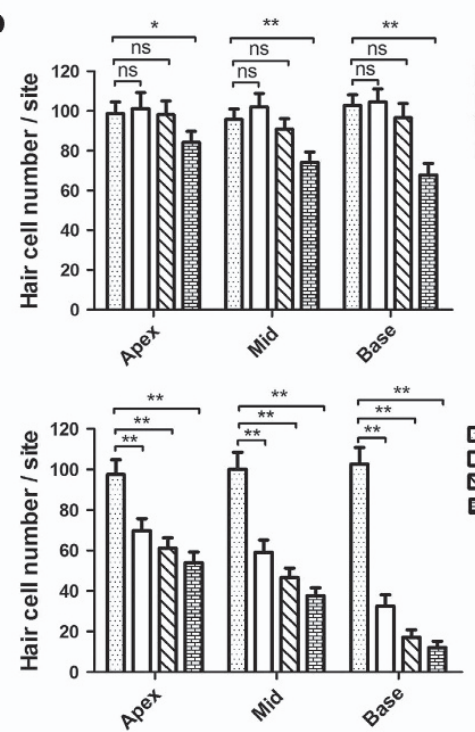

罚 Control

3 UM DDP $\times 24 h$

$20 \mathrm{uM}$ DDP $\times 24 \mathrm{~h}$

$30 \mathrm{uM}$ DDP $\times 24 \mathrm{~h}$
C

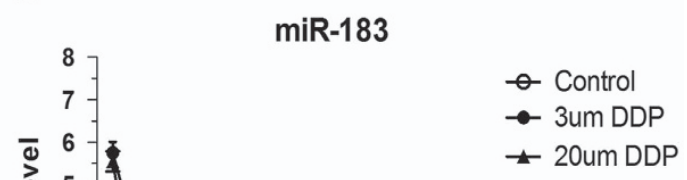

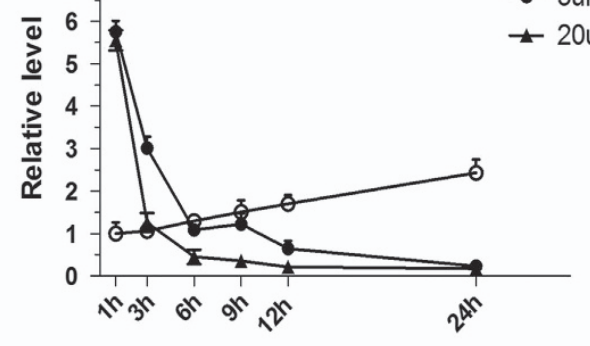

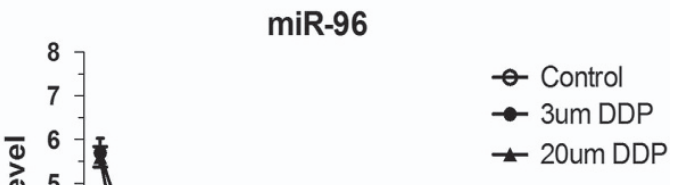

Figure 1 Turnover of miR-183, -96 , and -182 levels during cisplatin treatment. (a, b) Hair cell number did not change significantly after $24 \mathrm{~h}$ of treatment with 3 and $20 \mu \mathrm{M}$ cisplatin. Significant hair cell loss was observed at $48 \mathrm{~h}$ after cisplatin washout following treatment with 3,20 , and $30 \mu \mathrm{M}$ cisplatin. (c) MiR-183, -96 , and -182 levels increased significantly after $1 \mathrm{~h}$ of cisplatin treatment and decreased markedly in the following $23 \mathrm{~h}$. The miRNA level of the control group at $1 \mathrm{~h}$ was set as 1 . Data are shown as means \pm S.E. One-way ANOVA followed by Newman-Keuls test, ${ }^{* \star} P<0.01,{ }^{*} P<0.05$. Scale bar in bottom-right corner: $20 \mu \mathrm{m}$

treatment. No significant hair cell loss was observed in the 3 and $20 \mu \mathrm{M}$ groups at $\mathrm{O} \mathrm{h}$ after cisplatin treatment. However, when cochleae were cultured for a further $48 \mathrm{~h}$ after cisplatin washout, significant hair cell loss was observed at all cisplatin concentrations (Figures 1a and b).

To investigate the roles of miR-183, -96 , and -182 in cisplatininduced hair cell apoptosis, we monitored miR-183, -96, and -182 expression levels during $24 \mathrm{~h}$ of 3 and $20 \mu \mathrm{M}$ cisplatin treatment using quantitative reverse-transcription PCR (qRT-PCR). Interestingly, although the number of hair cells remained similar, we observed considerable turnover of miR-183, -96 , and -182 levels during the first $24 \mathrm{~h}$ of cisplatin treatment. The miR-183, -96 , and
-182 levels increased rapidly and peaked at $1 \mathrm{~h}$, then decreased rapidly during the following $5 \mathrm{~h}$. The miR-183/96/182 expression level decreased to lower than that of the cisplatin-untreated groups at $6 \mathrm{~h}$, and continued to decrease from 6 to $24 \mathrm{~h}$. Moreover, the rate of decrease in miR-183/96/182 expression was positively related to the concentration of cisplatin (Figure 1c). The miR-183, -96 , and -182 levels increased spontaneously in the control group during culture for $24 \mathrm{~h}$ (Figure 1c).

Overexpression of $\mathrm{miR}-182$ prevented cisplatin-induced hair cell loss in vitro. The marked turnover of miR-183/96/182 suggested their importance in hair cell death in the presence of 
cisplatin. We hypothesized that the elevation of miR-183, -96 , and -182 levels during the first hour is a self-defense response to the cytotoxicity of cisplatin and may protect hair cells. To test this hypothesis, miR-183, -96 , and -182 were overexpressed in cochlear explants by transfecting miRNA mimics using lipid transfection reagent before treatment with 3 or $20 \mu \mathrm{M}$ cisplatin. qRT-PCR was used to determine the transfection efficiency of miRNA mimics. After transfection with miR-183, -96, and -182 mimics, robust increases in miRNA levels were observed at days 1,3 , and 5 compared with the control group (Supplementary Figures $1 \mathrm{~A}-\mathrm{C})$, which indicated that the ectopically introduced miRNA mimics were maintained at a high level for at least 5 days. After transfection, cochlear explants were cultured in serum-free medium for $24 \mathrm{~h}$ before treatment with 3 or $20 \mu \mathrm{M}$ cisplatin for $24 \mathrm{~h}$. Surviving hair cells were counted $48 \mathrm{~h}$ after cisplatin washout. Interestingly, protective effects were evident only in the miR-182 overexpression group following treatment with $3 \mu \mathrm{M}$ cisplatin but not with $20 \mu \mathrm{M}$ cisplatin (Figures $2 \mathrm{a}-\mathrm{c}$ ). To determine whether overexpression of miR-182 could rescue hair cell death after cisplatin exposure, cochlear explants were transfected with miR-182 mimics after $24 \mathrm{~h}$ of treatment with $3 \mu \mathrm{M}$ cisplatin. No significant difference was observed in the miR-182 rescue group compared with the control group (Figure 2d).

Finally, to determine the effect of miR-182 knockdown on hair cell survival under cisplatin treatment, anti-miR-182 mimics were transfected to cochlear explants to knockdown endogenous miR-182. qRT-PCR showed that the miR-182 level was significantly inhibited at days 1,3 , and 5 after anti-miR-182 transfection (Supplementary Figure 1d). Hair cell counts showed no significant difference between the miR-182 knockdown group and the control group transfected with control oligos at $48 \mathrm{~h}$ after cisplatin washout (Figure 2e).

\section{Overexpression of miR-182 inhibited cisplatin-induced} mitochondrial-dependent apoptosis of hair cells in vitro. To assess cisplatin-induced hair cell apoptosis, we used immunofluorescence staining of cleaved caspase 3, a common executor in the apoptotic pathway. ${ }^{23}$ Cochlear explants were transfected with miR-182 mimics or control oligos, and then treated with $3 \mu \mathrm{M}$ cisplatin for $24 \mathrm{~h}$. Apoptotic hair cells were quantified $24 \mathrm{~h}$ after cisplatin washout. In addition, z-Val-Ala-Asp-fluoromethylketone (z-VAD-fmk), a a

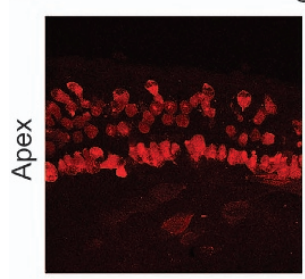

Control Oligo+3uM DDP
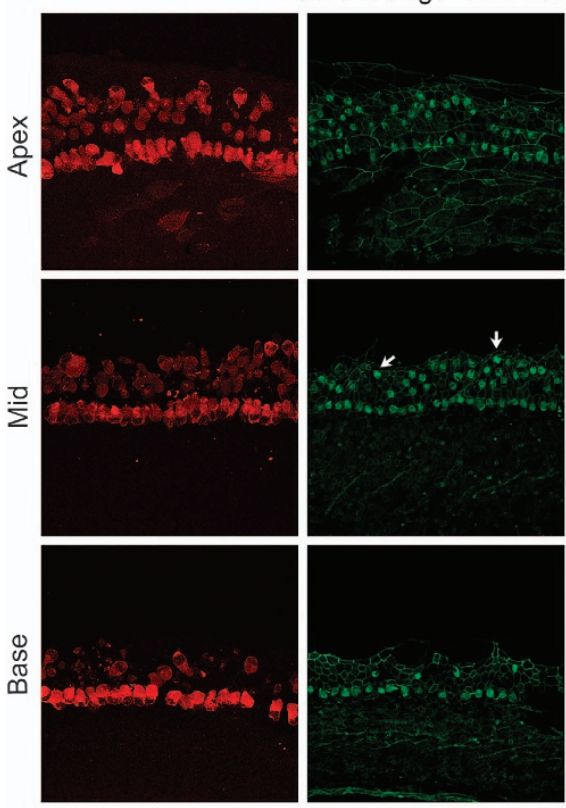

C

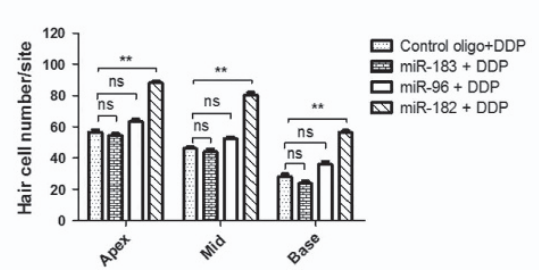

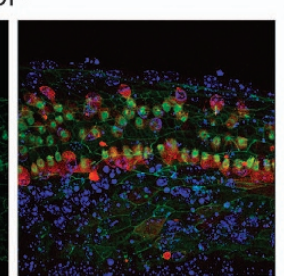
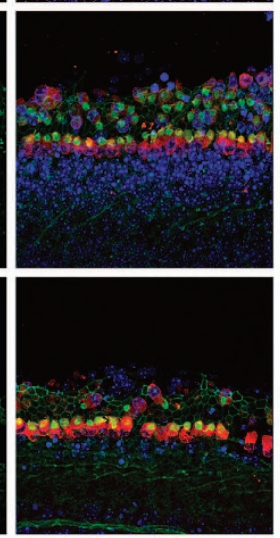

d
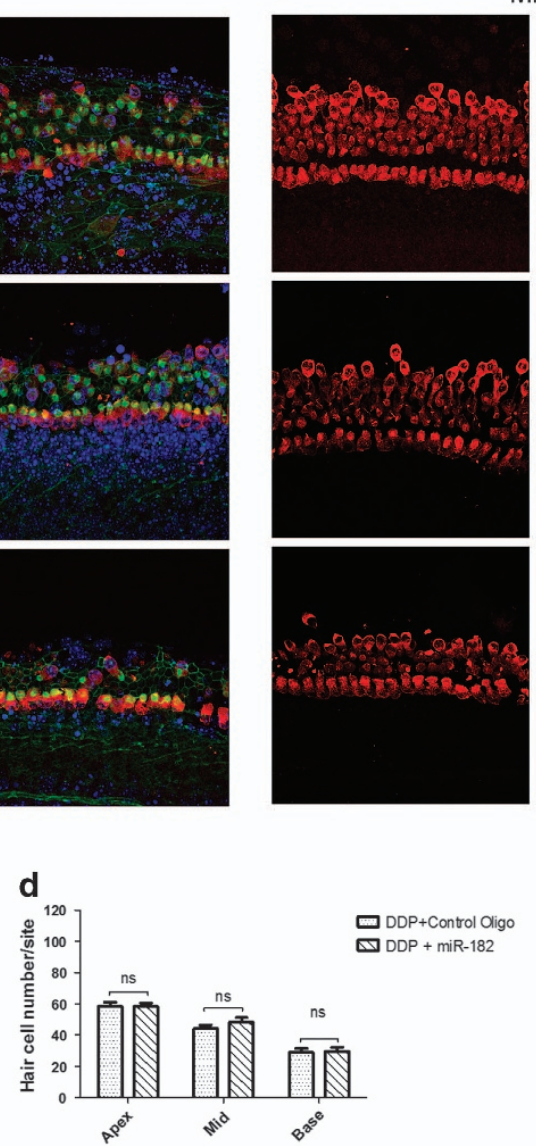

MiR-182 mimics+3uM DDP
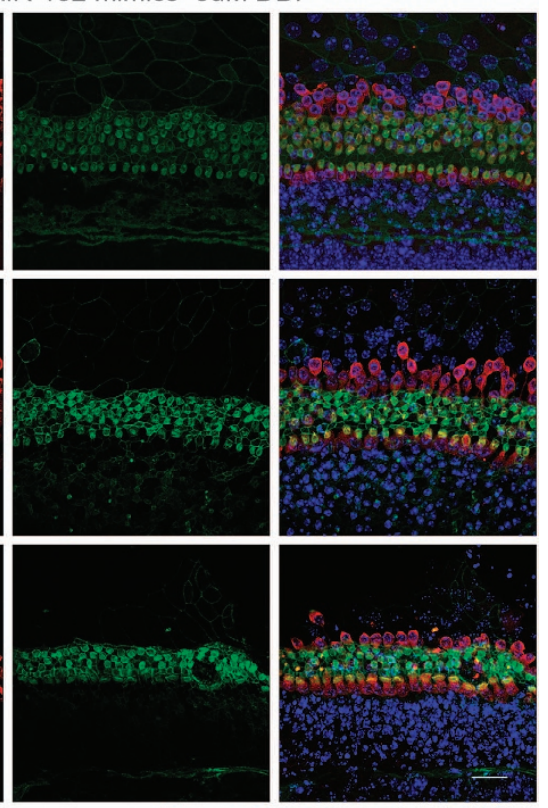

Myosin 7a / Phalloidin / DAPI

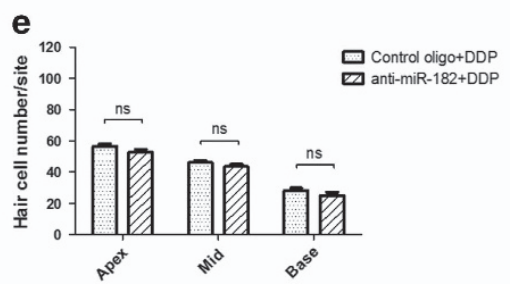

Figure 2 Overexpression of miR-182 before treatment with $3 \mu \mathrm{M}$ cisplatin significantly improved hair cell survival. (a-c) Surviving hairs were confirmed by phalloidin and myosin 7 a double staining. The stereocilia of many hair cells had been lost and the cuticular plates had shrunk (white arrowhead) after cisplatin treatment (a, b) Residual hair cell numbers at the apex, mid, and base turn in the miR-183 OE, miR-96 OE, miR-182 OE, and control groups $48 \mathrm{~h}$ after cisplatin washout (c). (d) Residual hair cell numbers in the miR-182 rescue and control groups. (e) Residual hair cell numbers in the miR-182 knockdown and control groups $48 \mathrm{~h}$ after cisplatin washout. Data are shown as means \pm S.E. Student's $t$-test and one-way ANOVA followed by Newman-Keuls test, ${ }^{* \star} P<0.01$. Scale bar in bottom-right corner: $20 \mu \mathrm{m}$. ns, no significance 


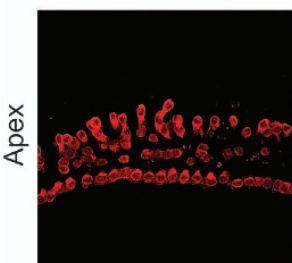

Control Oligo+3uM DDP
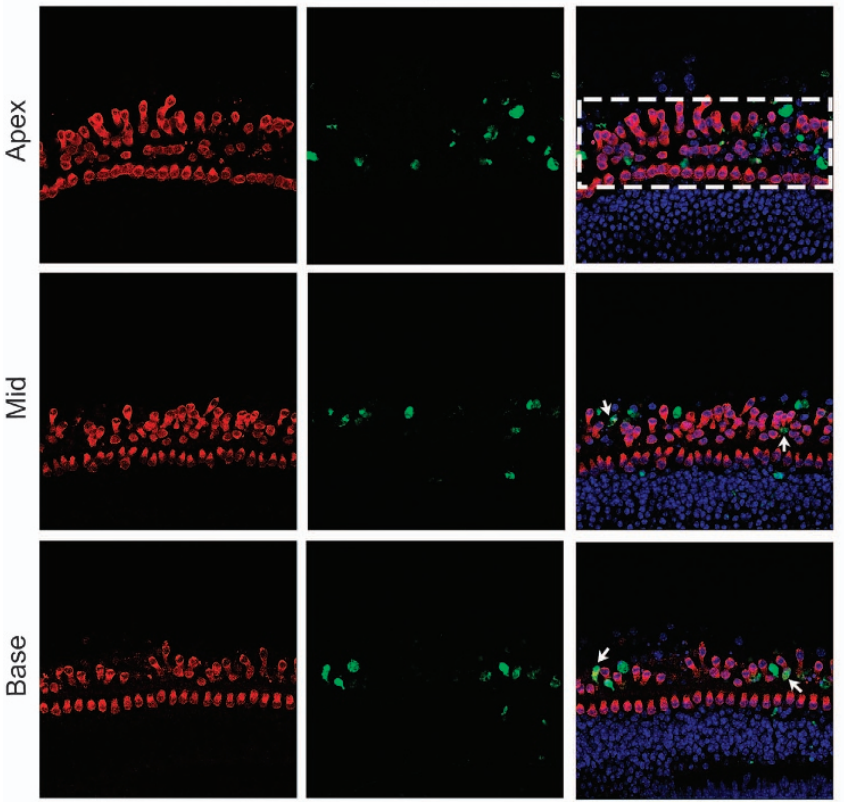

C

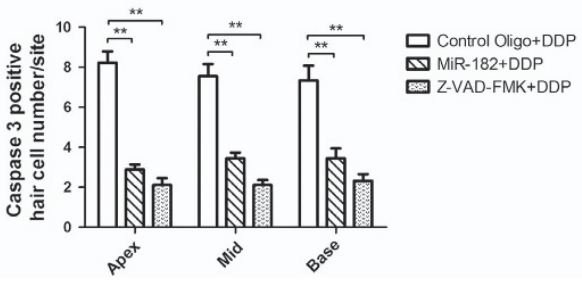

b

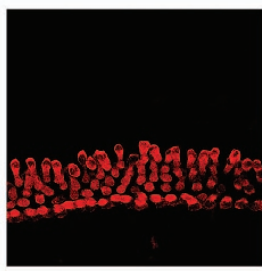

MiR-182 mimics+3uM DDP
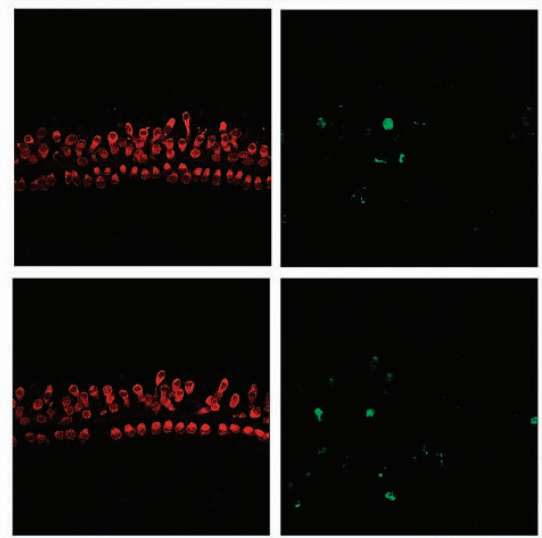

Myosin 7a / Caspase 3 / DAPI
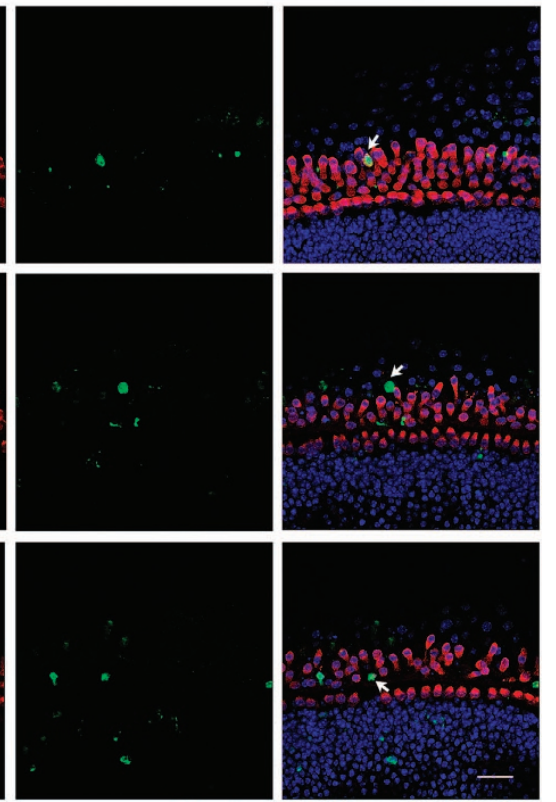

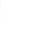

Figure 3 Overexpression of miR-182 significantly reduced cisplatin-induced hair cell apoptosis. (a-c) Caspase $3(+)$ cells in the white-dashed-line box are considered caspase $3(+)$ hair cells. Caspase $3(+)$ and Myo $7 \mathrm{a}(+)$ double-labeled cells (hair cells undergoing apoptosis) are indicated by white arrowheads (a, b). Numbers of apoptotic hair cells at the apex, mid, and base turn in the control group, miR-182 OE group, and z-VAD-fmk group (c). Data are shown as means \pm S.E. Student's $t$-test, ** $P<0.01$. Scale bar in bottom-right corner: $20 \mu \mathrm{m}$

broad-spectrum caspase inhibitor, which was shown to inhibit hair cell apoptosis in a mouse model in which hair cells undergo apoptotic self-degeneration, ${ }^{24}$ was used to determine the involvement of caspase-dependent apoptosis of hair cells under cisplatin treatment. Significantly fewer caspase 3-positive hair cells were observed in the miR-182 overexpression group $(2.95 \pm 0.83$ for apex $(n=27, P<0.01)$, $3.45 \pm 0.93$ for mid $(n=27, P<0.01)$, and $3.47 \pm 1.54$ for base $(n=27, P<0.01))$ and in the $z$-VAD-fmk group $(2.11 \pm 1.05$ for apex $(n=27, P<0.01), 2.26 \pm 0.78$ for mid $(n=27, P<0.01)$, and $2.34 \pm 1.02$ for base $(n=27, P<0.01))$ compared with the control group $(8.24 \pm 1.72$ for apex $(n=27), 7.65 \pm 1.85$ for mid $(n=27)$, and $7.37 \pm 2.28$ for base $(n=27)$; Figures $3 a-c)$.

The mitochondrial-dependent intrinsic pathway and the death-receptor-dependent extrinsic pathway are the two major apoptotic pathways. ${ }^{25}$ To investigate the effects of cisplatin treatment on these two apoptotic pathways in the inner ear, qRT-PCR, immunofluorescence staining, and western blotting were performed to assess the levels of several key apoptotic effectors, including BCL2-associated X protein (Bax), apoptotic peptidase activating factor 1 (Apaf-1), and caspase 9 of the intrinsic pathway, as well as FAS-associated protein with a death domain (FADD) and caspase 8 of the extrinsic pathway. At $24 \mathrm{~h}$ after cisplatin washout, relative Bax, Apaf-1, and caspase 9 mRNA (Figure 4a) and protein (Figures 4b and c) levels increased significantly, whereas those of FADD and caspase 8 were not significantly different from the control group (Figures $4 a$ and $d$ ).

To determine the effects of miR-182 overexpression on the intrinsic and extrinsic apoptotic pathways after cisplatin treatment, qRT-PCR and western blotting were performed. The increases in Bax, Apaf-1, and caspase 9 expression were significantly inhibited in the miR-182 overexpression group, whereas FADD and caspase 8 expression were unaffected (Figures $4 \mathrm{e}-\mathrm{g}$ ).

Mitochondria have a decisive role in the intrinsic apoptotic pathway. The mitochondrial transmembrane potential, which reflects mitochondrial function, was assessed by tetramethylrhodamine ethyl ester (TMRE) staining assay. ${ }^{26}$ The fluorescence intensity in the cisplatin-treated group was $0.31 \pm 0.07$-fold than that of the control group $(P<0.01$; Figure 4h). However, when transfected with miR-182 mimics before cisplatin treatment, the fluorescence intensity was $2.98 \pm 0.31$-fold higher than that of the control group transfected with control oligo $(P<0.01$; Figure $4 \mathrm{i})$. 
Overexpression of miR-182 did not alter the function of mechanotransduction channels in hair cells. Functional mechanotransduction is required for cisplatin-induced hair cell death in the zebrafish lateral line. ${ }^{27}$ To determine whether a

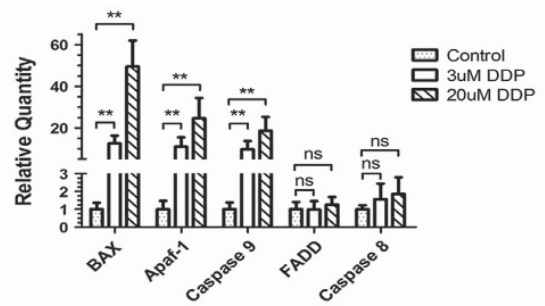

b
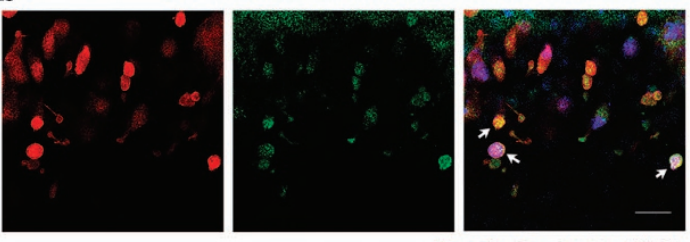

Myosin 7a / BAX / DAPI
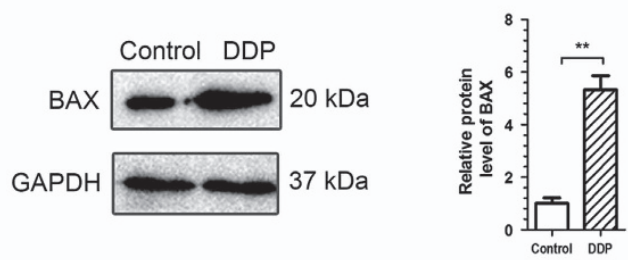

C
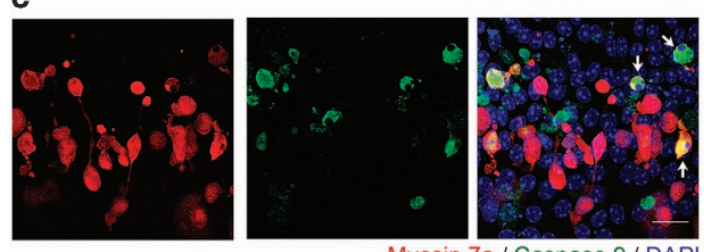

Myosin 7a / Caspase 9 / DAPI
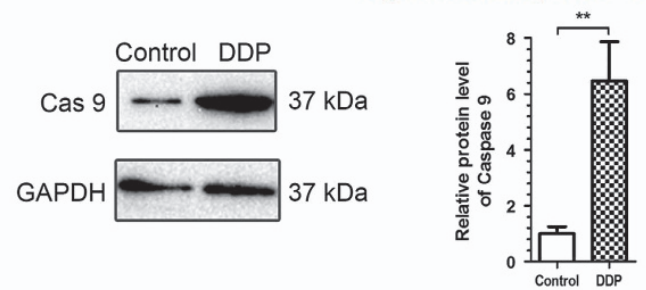

d
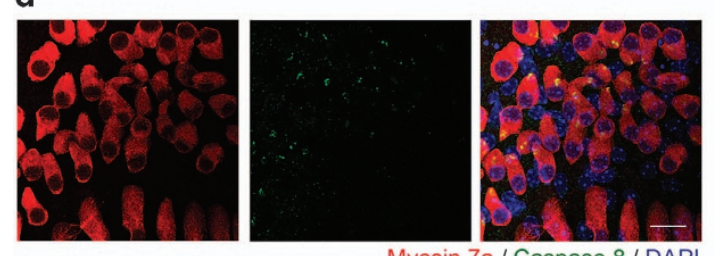

Myosin 7a / Caspase 8 / DAPI
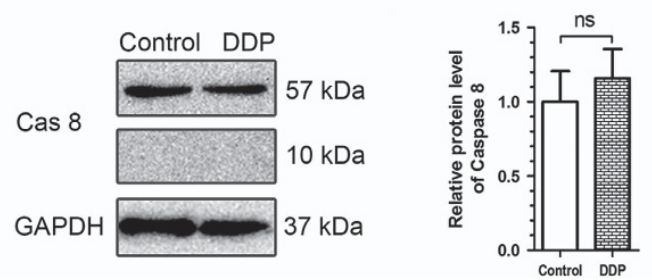

miR-182 protects hair cells from cisplatin-induced damage by reducing cisplatin uptake through blocking of mechanotransduction channels, we performed an FM 1-43 staining assay. Hair cells in the miR-182 overexpression group took up the

e

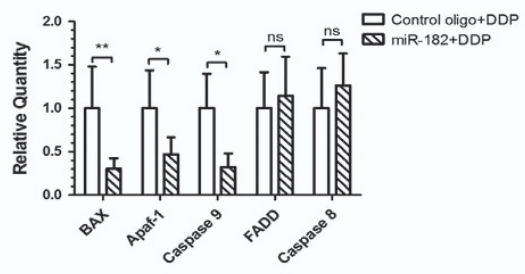

f

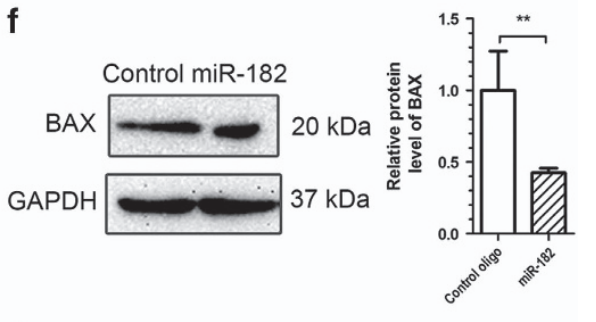

g

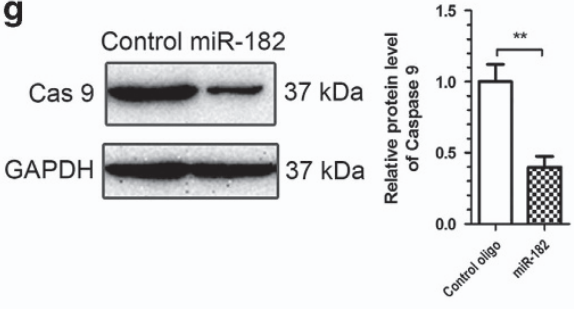

h

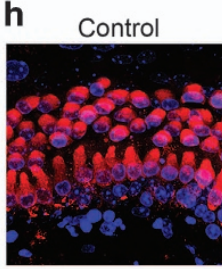

3uM DDP24h+24h

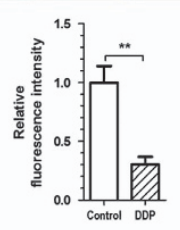

i

Control oligo+DDP

miR-182+DDP
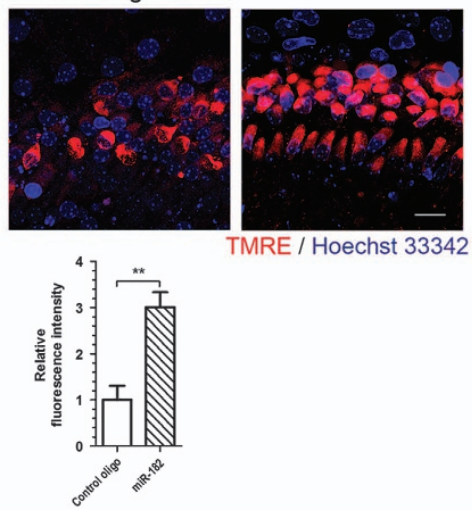
FM 1-43 dye, as well as normal hair cells and those in the cisplatin-only group. In addition, bright fluorescent punctae were seen at the top of hair cells where the mechanotransduction channels are located (Figures $5 a-d$ ), which indicated that they were functional.

MiR-182 protected hair cells against cisplatin-induced apoptosis through inhibition of FOXO3a. miRNAs implement their regulatory roles in animals and plants by posttranscriptional repression of their target genes. ${ }^{13}$ To screen for the underlying target gene of miR-182, we searched the miRanda-mirSVR and TargetScan 6.1 databases for proposed target genes of miR-182 that are involved in regulating apoptosis. We also retrieved previous reports of target genes of miR-182. Both FOXO3a (ref. 28) and breast cancer type 1 susceptibility protein (BRCA1) $)^{29}$ are validated targets of miR-182 and are related to apoptosis (Supplementary Figure 2). We performed qPCR to investigate the effect of cisplatin treatment on FOXO3a and BRCA1 expression in cochlear explants. FOXO1, a member of the FOXO protein superfamily reported to be regulated by miR-183 and $-96,{ }^{30,31}$ was also included. The mRNA levels of FOXO3a (Figure 6a) and FOXO1 (Supplementary Figure $3 A$ ) were significantly increased during $24 \mathrm{~h}$ of cisplatin treatment, but the expression level of BRCA1 was unaffected (Supplementary Figure $3 \mathrm{~B}$ ). Then, we performed immunofluorescent staining and western blotting to assess FOXO3a and FOXO1 protein levels in a spatial and quantitative manner. As a transcription factor, FOXO3a exerts its function by translocation into the nucleus. ${ }^{32}$ Before cisplatin treatment, the nuclei and cytoplasm of hair cells showed immunofluorescent staining for FOXO3a (Figure 6c, upper panel). After $24 \mathrm{~h}$ of cisplatin treatment, the fluorescence in hair cell nuclei increased markedly (Figure 6c, lower panel). However, no distinct fluorescent staining of FOXO1 in hair cell nuclei was observed before or after cisplatin treatment (Supplementary Figure 3D). Western blotting showed that the FOXO3a protein level increased gradually and reached $5.25 \pm 1.38$ fold $(n=3, P<0.01)$ higher than that of the control group after $24 \mathrm{~h}$ of cisplatin treatment. No significant increase in FOXO1 protein level was observed after cisplatin treatment (Supplementary Figure 3F).

Next, we explored the effects of miR-182 overexpression on cisplatin-induced $\mathrm{FOXO} 3 \mathrm{a}$ upregulation in hair cells. Overexpression of miR-182 did not inhibit the increase in FOXO3a (Figure 6b) and FOXO1 (Supplementary Figure 3C) mRNA levels induced by cisplatin treatment. However, immunofluorescent staining and western blotting showed significant inhibition of $\mathrm{FOXO} 3$ a protein in hair cell nuclei in the miR-182 overexpression group compared with the control group (Figures $6 \mathrm{~d}$ and f). Overexpression of miR-182 did not alter FOXO1 expression in hair cell nuclei (Supplementary Figure $3 \mathrm{E}$ and $\mathrm{G}$ ).

miRNAs induce post-transcriptional regulation of target genes by forming RNA-induced silencing complexes (RISCs) with Argonaute 2 (Ago2) protein. ${ }^{33,34}$ To elucidate the direct interaction of miR-182 and FOXO3a, RNA-binding protein immunoprecipitation (RIP) analyses were performed using
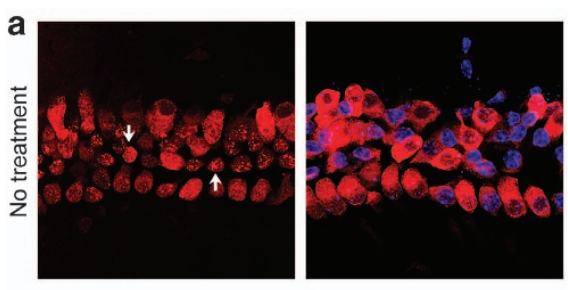

C
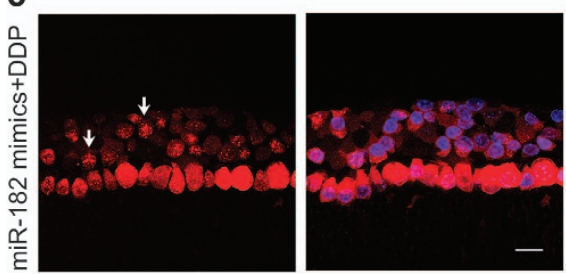
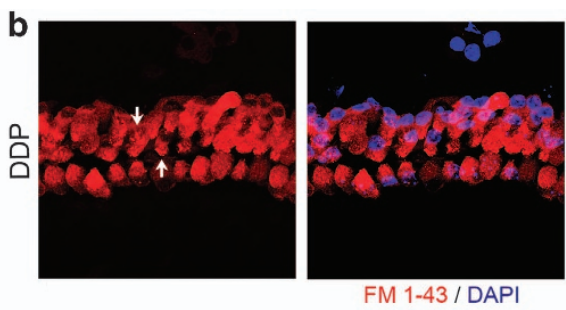

d

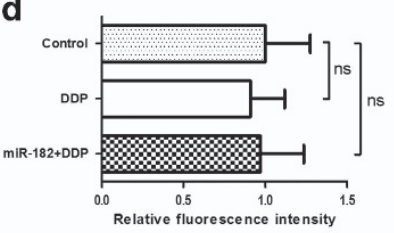

Figure 5 Overexpression of miR-182 did not alter the function of the mechanotransduction channels of hair cells. (a-d) After transfection with miR-182 mimics followed by treatment with cisplatin for $24 \mathrm{~h}$ (c), hair cells took up FM 1-43 to a similar level as the control group (a) and the cisplatin-only group (b). Bright fluorescent punctae (white arrowheads) show the locations of mechanotransduction channels. Scale bar in bottom-right corner: $20 \mu \mathrm{m}$. ns, no significance

Figure 4 Overexpression of miR-182 inhibited cisplatin-induced mitochondrial-dependent apoptosis of hair cell. (a) Bax, Apaf-1, and caspase 9 levels were significantly increased at $24 \mathrm{~h}$ of cisplatin washout, whereas FADD and caspase 8 levels were not significantly different. (b, c) At $24 \mathrm{~h}$ of cisplatin washout, clear induction of Bax and caspase 9 was exhibited in hair cells (white arrows indicate the double staining of Bax and myosin $7 a$ (b, upper panel) or caspase 9 and myosin $7 a$ (c, upper panel)). Western blot shows the increased protein levels of Bax (b, lower panel) and caspase 9 (c, lower panel) after cisplatin treatment. (d) No significant of caspase 8 expression in hair cells or increased caspase 8 protein level after cisplatin treatment. (e) The mRNA levels of Bax, Apaf-1, and caspase 9 (e) and the protein levels of Bax and caspase 9 (ff, $\mathbf{g}$ ) were significantly reduced in the miR-182 overexpression group at $24 \mathrm{~h}$ after cisplatin washout, whereas FADD and caspase $8 \mathrm{mRNA}$ levels were not significantly different (e). (h) Significant reduction of TMRE staining in hair cells treated with cisplatin. (i) The fluorescence intensity of TMRE staining in miR-182 overexpression group is significantly higher than control group. Data are shown as means \pm S.E. Student's $t$-test and one-way ANOVA followed by Newman-Keuls test, ${ }^{\star \star} P<0.01,{ }^{*} P<0.05$. Scale bar in bottom-right corner: $10 \mu \mathrm{m}$ (b, c, d). Scale bar in bottom-right corner: $20 \mu \mathrm{m}$ (h, i). ns, no significance 

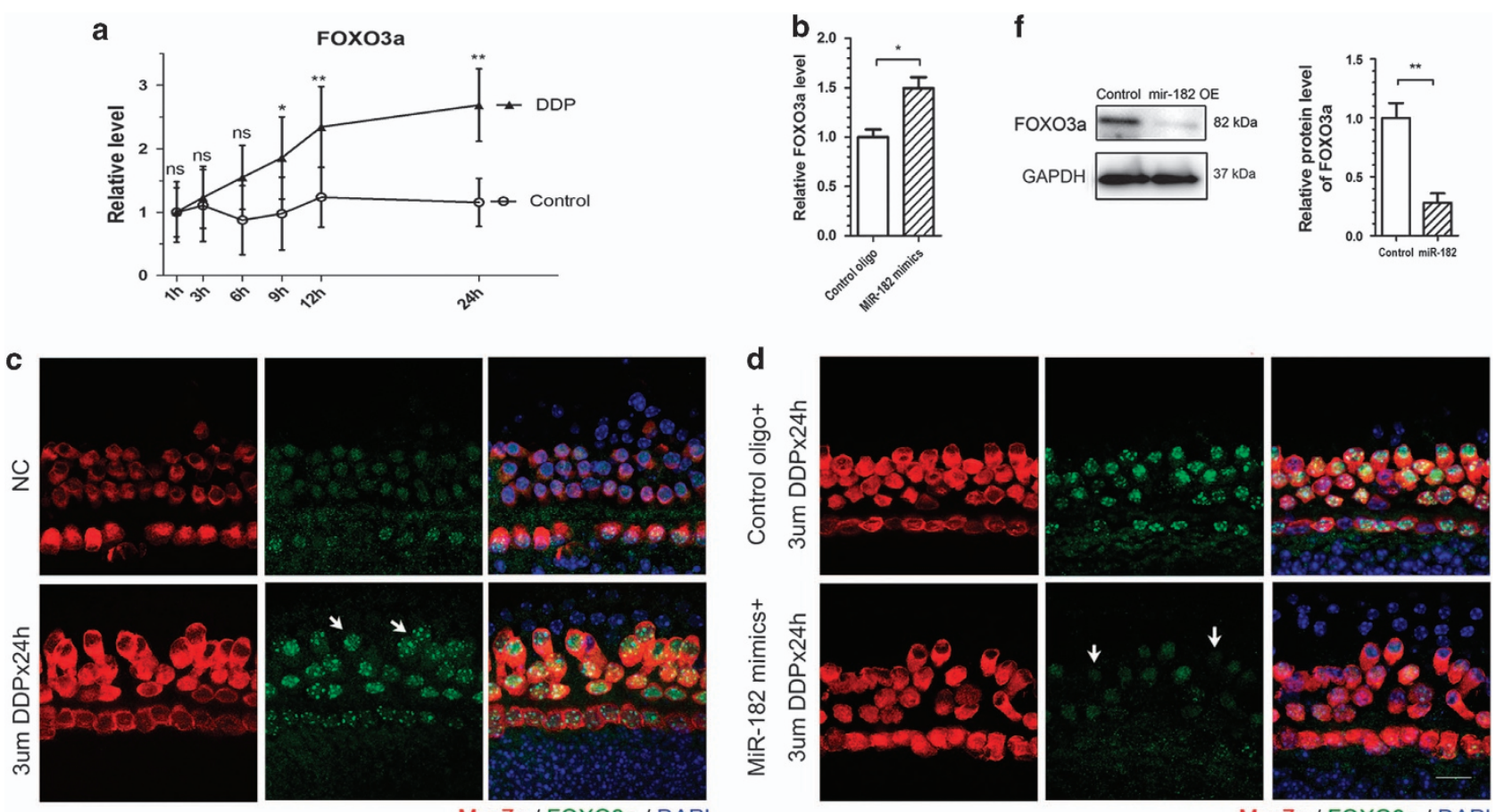

Myo7a / FOXO3a / DAPI

Myo7a / FOXO3a / DAPI

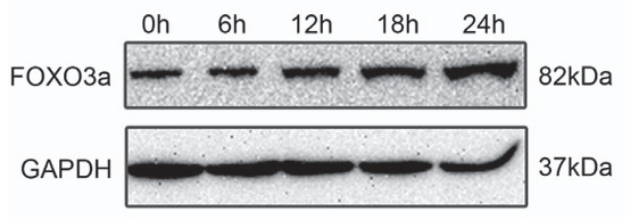

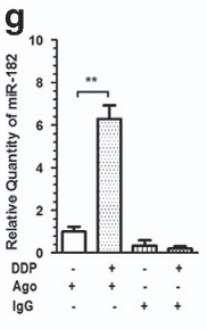
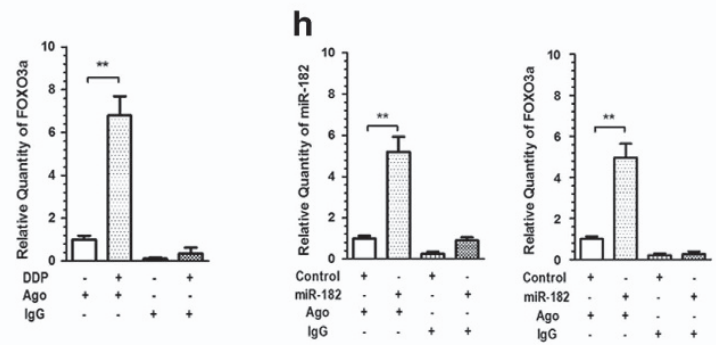

Figure 6 MiR-182 protects hair cells from cisplatin-induced apoptosis through inhibition of FOXO3a. (a) The FOXO3a mRNA levels increased gradually during the $24 \mathrm{~h}$ of cisplatin treatment. (b) Transfection with miR-182 mimics before treatment with cisplatin for $24 \mathrm{~h}$ did not inhibit the increase in FOXO3a mRNA level. (c) FOXO3a expression is significantly upregulated in hair cell nuclei. Bright fluorescence indicates chromosome (white arrowhead). (d) FOXO3a expression is significantly lower in the miR-182 OE group (white arrowhead) compared with the control group. (e) Western blot analysis showed that the FOXO3a protein level were $1.02 \pm 0.34,0.85 \pm 0.52,1.87 \pm 0.64$ ( $P<0.01, n=3$ ), $3.66 \pm 1.23(P<0.01, n=3)$, and $5.25 \pm 1.38$-fold $(P<0.01, n=3)$ at the $0,6,12,18$, and $24 \mathrm{~h}$, respectively, of cisplatin treatment compared with the control group. (f) After transfection with miR-182 mimics followed by treatment with cisplatin for $24 \mathrm{~h}$, the FOXO3a protein level of the miR-182 OE group was $0.28 \pm 0.08$-fold $(P<0.01, n=3)$ that of the control group. (g) The relative level of miR-182 and FOXO3a mRNA co-precipitated with Ago2 protein was $6.28 \pm 0.64$-fold $(P<0.01, n=3)$ and $6.8 \pm 0.89$-fold than that of the control group, respectively, after $24 \mathrm{~h}$ of cisplatin treatment. (h) After transfection with miR-182 mimics followed by treatment with cisplatin for $24 \mathrm{~h}$, the level of miR-182 and FOXO3a mRNA co-precipitated with Ago2 was $5.2 \pm 0.72$-fold $(P<0.01, n=3)$ and $4.97 \pm 0.67$-fold $(P<0.01, n=3)$ than that of the control group, respectively. Data are shown as means \pm S.E. Student's $t$-test, ${ }^{\star *} P<0.01,{ }^{*} P<0.05$. Scale bar in bottom-right corner: $10 \mu \mathrm{m}$. ns, no significance

rabbit anti-Ago2 antibody to co-precipitate miRNA and its target mRNAs bound to RISC. After treatment with cisplatin for $1 \mathrm{~h}$, the relative miR-182 and FOXO3a mRNA levels coprecipitated with Ago2 protein were $6.28 \pm 1.15$-fold $(n=3$, $P<0.01)$ and $6.8 \pm 1.54$-fold $(n=3, P<0.01)$, respectively, greater than that in the undamaged control group (Figure $6 \mathrm{~g}$ ), confirming the interaction of miR-182 and $\mathrm{FOXO} 3$ a during cisplatin treatment. Next, we explored whether the downregulation of $\mathrm{FOXO} 3 \mathrm{a}$ in the miR-182 overexpression group was due to a direct interaction of miR-182 and FOXO3a. After transfection with miR-182 mimics and treatment with cisplatin for $1 \mathrm{~h}$, the relative levels of miR-182 and FOXO3a mRNA co-precipitated with Ago2 protein were $5.2 \pm 1.25$-fold $(n=3$, $P<0.01)$ and $4.97 \pm 1.16$-fold $(n=3, P<0.01)$, respectively, greater than the control group (Figure 6h), confirming direct repression of FOXO3a by miR-182.

MiR-182 attenuated the synergetic effect of PI3K inhibitor and cisplatin on hair cell loss. The PI3K-AKT pathway is recognized as a main regulator of the FOXO protein family. AKT inhibits the function of FOXO as a transcription factor by preventing translocation to nuclei and binding to promoter regions through phosphorylation of FOXO protein. ${ }^{35,36}$ The PI3K inhibitor LY294002 aggravates gentamicin-induced hair cell loss, ${ }^{37}$ but the exact mechanism has not been elucidated. To determine the effect of PI3K inhibitor on cisplatin-induced hair cell loss, cochlear explants were treated with cisplatin alone or in combination with LY294002, and similar 

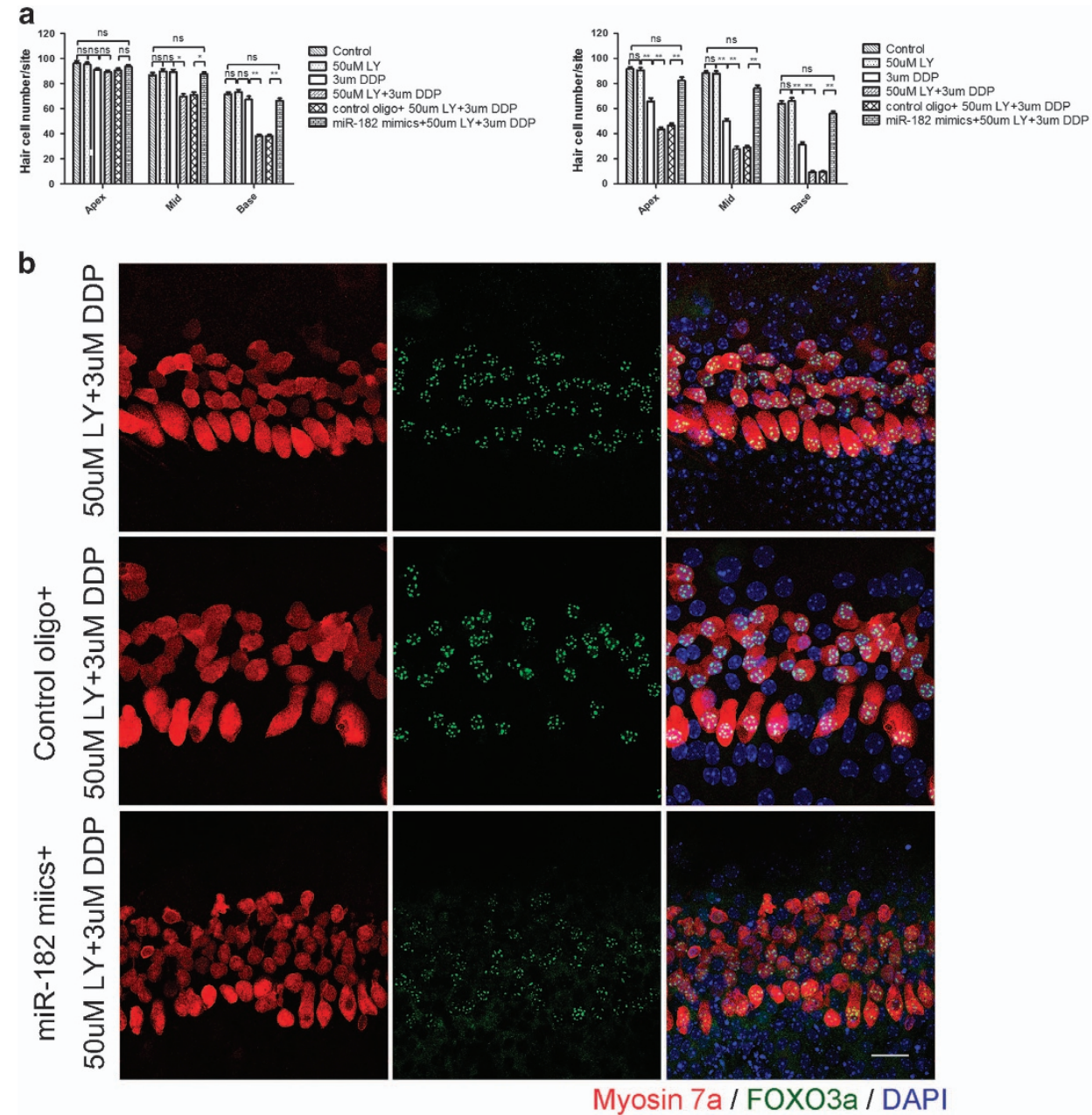

Figure 7 MiR-182 attenuated the synergetic effect of PI3K inhibitor and cisplatin on hair cell loss. (a) The synergetic effect of PI3K inhibitor and cisplatin on hair cell loss and the protective effect of miR-182. Loss of hair cells was significantly exacerbated when organ of Corti explants were treated with LY294002 and cisplatin in combination at $24 \mathrm{~h}$. Transfection with miR-182 mimics before LY294002 and cisplatin treatment significantly improved hair cell survival. (b) Intense expression of FOXO3a in the hair cell nuclei in cochlear explants treated with cisplatin and LY294002 together (b, upper panel) and control oligo group (b, middle panel), whereas lower fluorescence intensity in hair cell nuclei was observed in miR-182 overexpression group (b, lower panel). Data are shown as means \pm S.E. One-way ANOVA followed by Newman-Keuls test, ${ }^{* *} P<0.01$. Scale bar in bottom-right corner: $20 \mu \mathrm{M}$. ns, no significance

aggravation of hair cell loss was observed in the cisplatin and LY294002 combination group compared with the cisplatin-alone group (Figure 7a). In addition, clear FOXO3a expression was detected in the hair cell nuclei by immunofluorescence staining when treated with LY294002 and cisplatin together (Figure 7b). Next, we transfected cochlear explants with miR-182 mimics before LY294002 and cisplatin treatment to determine the effect of miR-182 overexpression on hair cell loss. Interestingly, overexpression of miR-182 significantly improved hair cell survival in the presence of both LY294002 and cisplatin (Figure 7a). Lower FOXO3a fluorescence staining in hair cell nuclei was observed in the miR-182 overexpression group compared with the control group transfected with control oligo (Figure $7 b$, lower panel).

\section{Discussion}

Cisplatin is one of the most widely used antitumor drugs. However, its poor selectivity toward tumor cells results in serious side effects, such as nephrotoxicity and ototoxicity. There is at present no effective medical treatment for ototoxicity. ${ }^{38}$ Present trials are at the pre-clinical stage, mainly because of concerns regarding interference with the antitumor effect of cisplatin. Thus, novel protective agents with higher selectivity toward non-cancerous cells are required.

miRNAs have important roles in regulating cell death, particularly apoptosis. Efforts have been made to improve cell survival by modulating miRNA levels, which yielded promising results. ${ }^{39-41}$ In the inner ear, a recent study identified miR-207, which directly targets Akt3, as a pro-apoptotic miRNA in an ionizing radiation-induced hair cell death model. ${ }^{42}$ Moreover, miR-34a/SIRT1/p53 signaling is activated while that of the miR-183 family is downregulated during age-related hair cell apoptosis. ${ }^{43,44}$ Thus, protecting hair cells against apoptosis by downregulating pro-apoptotic miRNAs or upregulating anti-apoptotic miRNAs is a feasible strategy.

Previous studies indicated important roles for the miR-183, -96, and -182 cluster in inner ear development and 
pathogenesis. ${ }^{45-47}$ We observed rapid turnover of miR-183, -96 , and -182 levels during the first $24 \mathrm{~h}$ of cisplatin treatment. The majority of studies have reported that the miR-183 family exerts a protective effect against apoptosis; however, others have reported that miR-183, -96, and -182 facilitate apoptosis. ${ }^{48-50}$ We hypothesized that the rapid elevation of miR-183, -96, and -182 levels during the first hour of cisplatin treatment was due to the self-defense response of hair cells to cisplatin. Activation of the apoptotic cascade is decided by the balance between the pro-apoptotic and anti-apoptotic factors within and around cells. If cisplatin-induced pro-apoptotic effects overwhelm the intrinsic defensive mechanism of hair cells, irreversible apoptosis will result. Thus, miR-183, -96, and -182 levels decreased markedly between 2 and $24 \mathrm{~h}$ after cisplatin treatment, leading to hair cell apoptosis. Moreover, miR-183, -96, and -182 levels increased spontaneously in the control group. This was likely due to self-adaptation of the cochlear explants upon transfer from in vivo to in vitro, which may facilitate hair cell survival during the change in growth environment.

Assessment of the effects of miRNA overexpression partially validated our hypothesis of a protective effect of miR-182 against cisplatin-induced apoptosis of hair cells. Overexpression of miR-182 before cisplatin treatment significantly improved hair cell survival; however, overexpression of miR-183 and -96 failed to increase the hair cell survival rate. Although miR-183, -96 , and -182 are located in a genomic DNA fragment of $<4 \mathrm{~kb}$ and co-transcribed from genomic DNA, they do not target the same group of genes. ${ }^{51}$ miRNAs regulate their targets by partial complementary binding to the 3 '-UTR) of mRNAs with their 'seed' sequence, ${ }^{52}$ and the 'seed' sequences of miR-183, -96 and, -182 are different, so their targets are different. Moreover, one miRNA could target a group of genes, so we conjecture that the miR-183, -96 , and -182 cluster is co-transcribed to maintain the balance of a larger group of genes. Thus, their functions are diverse and complementary rather than overlapping. In addition, the protective effect of miR-182 was observed only in organ of Corti explants treated with a low concentration $(3 \mu \mathrm{M})$ of cisplatin, not a high concentration $(20 \mu \mathrm{M})$. This reflects the notion that miRNAs regulate their target genes in a 'mild' pattern. ${ }^{53,54}$

We observed significant increases in the expression of Bax, Apaf-1, and caspase 9, three key effectors of the intrinsic apoptotic pathway, after $24 \mathrm{~h}$ of cisplatin treatment, whereas the levels of FADD and caspase 8, dominant members of the death-receptor-dependent extrinsic pathway, were not significantly changed. Bax is a pro-apoptotic factor that initiates the intrinsic apoptotic pathway by permeabilizing the mitochondrial outer membrane. ${ }^{55}$ Apaf- 1 is another important factor responsible for activating caspase 9 in the intrinsic apoptotic pathway. ${ }^{56}$ Loss of mitochondrial transmembrane potential was observed using a TMRE staining assay when organ of Corti explants were treated with cisplatin. These findings are consistent with previous reports that the intrinsic mitochondrial-dependent pathway is the dominant pathway in cisplatin-induced hair cell apoptosis. ${ }^{57}$ Furthermore, overexpression of miR-182 before cisplatin treatment significantly inhibited the increase of Bax, Apaf-1, and caspase 9, but not of FADD and caspase 8, expression, as well as the increased fluorescence intensity in the TMRE staining assay, indicating that miR-182 protects hair cells from cisplatin-induced apoptosis by inhibiting the intrinsic apoptotic pathway.

Uptake of cisplatin is the initial and pivotal event in its cytotoxicity. ${ }^{2}$ Cisplatin enters hair cells through a variety of routes, including copper transporters, organic cation transporters, and mechanotransduction channels. ${ }^{58,59}$ In our study, surviving hair cells maintained their ability to take up FM 1-43, suggesting that the protective effect of miR-182 on hair cells is not mediated by blocking mechanotransduction channels.

Immunofluorescence staining and western blotting yielded spatial and quantitative evidence that $\mathrm{FOXO} 3 \mathrm{a}$ participates in cisplatin-induced hair cell apoptosis. FOXO3a is a proapoptotic transcription factor that functions by activating BIM, a pro-apoptotic member of the BCL-2 protein family. ${ }^{60,61}$ BIM activates Bax to induce mitochondrialdependent apoptosis. ${ }^{62}$ We observed marked elevation of FOXO3a and Bax expression during the initial phase of cisplatin-induced hair cell apoptosis. Overexpression of miR-182 reduced the expression of FOXO3a in hair cell nuclei. Moreover, the co-precipitation of miR-182 and FOXO3a mRNA by RIP assay indicated the direct regulation of FOXO3a by miR-182 in cisplatin-induced hair cell apoptosis. Thus, we believe that miR-182 suppresses hair cell apoptosis through direct inhibition of $\mathrm{FOXO3a.}$

Finally, the finding that overexpression of miR-182 attenuates the synergetic effect of a PI3K inhibitor and cisplatin on hair cell loss revealed the underlying mechanism. PI3K inhibitor enhances cisplatin-induced hair cell apoptosis by reducing the phosphorylation of FOXO3a by PI3K-AKT. Overexpression of miR-182 repressed the expression of FOXO3a, a pro-apoptotic transcription factor and direct target of the PI3K-AKT signaling pathway, which alleviated hair cell death.

In summary, we found that among the miR-183/96/182 family, overexpression of only miR-182 enhanced hair cell survival during treatment with a low concentration $(3 \mu \mathrm{M})$ of cisplatin in vitro. The protective effect was achieved by inhibiting intrinsic mitochondrial-dependent apoptosis via repression of $\mathrm{FOXO} 3 \mathrm{a}$. Our findings indicate the possibility of protecting hair cells before cisplatin therapy using endogenous, tissue-specific miRNAs. These findings may provide new therapeutic targets for the prevention of cisplatin-induced hair cell death, and may ameliorate the retardant effect of protective agents against the antitumor effect of cisplatin. However, the precise in vivo effect and whether miRNA treatment would be effective against the therapeutic dose of cisplatin warrant further studies.

\section{Materials and Methods}

Animals. Postnatal day $0-3 \mathrm{BALB} / \mathrm{c}$ mice of both sexes were obtained from the Department of Laboratory Animal Science of Fudan University. The care and use of animals were in strict accordance with the 'Guiding Directive for Humane treatment of Laboratory Animals' issued by the Chinese National Ministry of Science and Technology. The Institutional Animal Care and Use Committee of Fudan University approved all procedures. All possible efforts were made to minimize the number of animals used and their suffering.

Organ of Corti explants. Cochlear cultures were obtained as described previously. ${ }^{63,64}$ Briefly, mice were killed by decapitation. The organs of Corti were dissected from cochleae in ice-cold phosphate-buffered saline (PBS; HyClone, 
Logan, UT, USA) and placed on glass coverslips pre-coated with poly-D-lysine (Sigma-Aldrich, St Louis, MO, USA). Cultures were maintained in DMEM/F-12 medium (Gibco, Carlsbad, CA, USA) supplemented with N2 and B27 (both from Invitrogen, Carlsbad, $\mathrm{CA}, \mathrm{USA}$ ) at $37^{\circ} \mathrm{C}$ in a $5 \% \mathrm{CO}_{2}$ atmosphere. Fetal bovine serum (5\%; Invitrogen) was added to the medium for only the first $24 \mathrm{~h}$ of culture to facilitate cell attachment.

Cisplatin treatment, miRNA mimic transfection, z-VAD-fmk, and LY294002 treatment. All drugs and oligonucleotides were diluted in serumfree culture medium. Three concentrations of cisplatin (Sigma; 3, 20, and $30 \mu \mathrm{M}$ ) were used in this study. Cochlear explants were cultured in cisplatin-containing medium for $24 \mathrm{~h}$ and washed three times for 5 min each in PBS following completion of cisplatin treatment.

miRNA mimics and inhibitors were synthesized by GenePharma Co, Ltd. (Shanghai, China). The sequences were as follows: miR-183 (5'-UAUGGCACUGGUAGAAUUCACU-3'); miR-96 (5'-UUUGGCACUAGCACAUUUUUGCU-3'); miR-182 (5'-UUUGGCAAUGGUAGAACUCACACCG-3'); anti-miR-182 (5'-CGGUGUGAGUUCUACCAUUGCCAAA- $3^{\prime}$ ); and control (5'-UUGUACUACACAAAAGUAGUC-3'). Oligonucleotides were transfected to organ of Corti explants using the K2 transfection system (Biontex, München/Laim, Germany) following the manufacturer's instructions at $80 \mathrm{nM}$ for miRNA mimics and $100 \mathrm{nM}$ for miRNA inhibitors. The cochlear explants were transfected with miRNA mimics or inhibitors for $24 \mathrm{~h}$. After washing in PBS three times for 5 min each, cochlear explants were cultured in serumfree medium for a further $24 \mathrm{~h}$ and then treated with cisplatin.

The cochlear explants were incubated with z-VAD-fmk (100 $\mu \mathrm{M}$; Apexbio, Boston, MA, USA) for entire culture duration.

LY294002 (50 $\mu$ M; Selleck Chemicals, Houston, TX, USA) was applied to cochlear explants alone or together with $3 \mu \mathrm{M}$ cisplatin for $24 \mathrm{~h}$ as reported previously ${ }^{37}$ to assess their effects on hair cell loss.

Immunofluorescence. Cochlear explants were fixed in $4 \%$ paraformaldehyde for 10 min then washed thoroughly in PBS. After permeabilization in $0.5 \%$ Triton $\mathrm{X}-100$ in PBS for 30 min and blocking in 10\% donkey serum in PBS for $1 \mathrm{~h}$ at room temperature, the explants were incubated with the primary antibody overnight at $4{ }^{\circ} \mathrm{C}$. The primary antibodies used in this study were as follows: rabbit polyclonal anti-myosin 7a (1:500) (Proteus Biosciences, Ramona, CA, USA); mouse monoclonal anti-myosin 7a (1:500) (Developmental Studies Hybridoma Bank, lowa City, IA, USA); rabbit polyclonal anti-cleaved caspase 3 (1:400) (Cell Signaling Technology Inc., Beverly, MA, USA); rabbit monoclonal anti-Bax (1:400) (Cell Signaling Technology); rabbit monoclonal anti-caspase 9 (1:500) (Cell Signaling Technology); rabbit monoclonal anti-caspase 8 (1:200) (Cell Signaling Technology); rabbit monoclonal anti-FOXO1 (1:200) (Cell Signaling Technology); and rabbit monoclonal anti-FOXO3a (1:500) (Cell Signaling Technology). Primary antibodies were decanted in PBS and detected using TRITC- or Alexa Fluor 488-conjugated secondary antibodies (1:800) (Jackson ImmunoResearch, West Grove, PA, USA). Culture explants were stained with Alexa Fluor 488-conjugated phalloidin (1:800) (Invitrogen) for $40 \mathrm{~min}$ to label the hair bundles and cuticular plates of hair cells. Cell nuclei were counterstained with DAPI (Invitrogen). All fluorescence images were obtained using a Leica TCS SP8 confocal laser-scanning microscope (Leica, Heidelberg, Germany).

Enumeration of surviving and apoptotic hair cells. Myosin 7a- and Alexa Fluor 488-conjugated phalloidin staining were used for quantitative analysis of surviving hair cells after cisplatin treatment. Caspase 3 staining was used to label apoptotic cells. Caspase 3-positive cells located within the four rows of hair cells and on the same plane as myosin-7a-positive hair cells were counted as hair cells undergoing apoptosis. The numbers of surviving and apoptotic hair cells in each $\times 800$ microscopic field $(\sim 150 \mu \mathrm{m}$ along the long axis of the cochlear duct) were counted. Three microscopic fields were randomly selected from the apical, middle, and basal turns in each cochlear explant. At least nine cochleae from each experimental group from three independent experiments were evaluated.

Quantitative reverse-transcription PCR. Six cochlear cultures from each experimental group were pooled for RNA extraction. Total RNA was extracted using TRIzol reagent (Invitrogen) following the manufacturer's instructions. The quantity and quality of RNA were assessed using a Nanodrop 2000 spectrophotometer (Thermo Scientific, Waltham, MA, USA) and $0.8 \%$ agarose gel electrophoresis. qRT-PCR of miRNAs was performed using the polyA-tailing method as reported previously. ${ }^{65,66}$ One microgram of total RNA was tailed using Escherichia coli polyA polymerase (New England Biolabs, Ipswich, MA, USA). cDNA was synthesized using the GoScript Reverse Transcription System (Promega, Madison, WI, USA). Reverse transcription (RT) of miRNAs was conducted using an anchor RT primer. mRNAs were reverse-transcribed using the RT primer provided in the RT kit. qPCR was performed using GoTaq qPCR Master Mix (Promega) on an ABI 7500 Real-Time PCR system (Applied Biosystems, Foster City, CA, USA). All primers used in this study are listed in Table 1. Small nuclear RNA U6 and glyceraldehyde-3-phosphate dehydrogenase (GAPDH) were used as internal controls for miRNA and mRNA quantification, respectively. Relative quantities were calculated using the 2- $\Delta \Delta$ CT method. ${ }^{67}$

TMRE staining assay. Cochlear explants were removed from the culture medium and briefly washed in PBS, followed by incubation in TMRE (100 nM in

Table 1 Primers used in reverse transcription and qPCR for miRNAs and mRNAs

\section{Name}

Sequence

Anchor RT primer

Universal resverse primer

U6 forward

MiR-183 forward

MiR-96 forward

MiR-182 forward

Bax forward

Bax resverse

Apaf-1 forward

Apaf-1 resverse

Caspase 9 forward

Caspase 9 reverse

FADD forward

FADD reverse

Caspase 8 forward

Caspase 8 resverse

FOXO1 foward

FOXO1 reverse

FOXO3 forward

FOXO3 reverse

BRCA1 forward

BRCA1 reverse

GAPDH forward

GAPDH reverse

5'-GCTGTCAACGATACGCTACCTAACGGCATGACAGTG(T)15V-3'

5'-GCTGTCAACGATACGCTACCTA-3'

5'-CGCTTCGGCAGCACATATACTAA-3'

5'-GTATGGCACTGCTAGAATTCACT-3

5'-TTTGGCACTAGCACATTTTTTGC-3'

5'-TGGCAATGGTAGAACTCACACC-3'

5'-TGAAGACAGGGGCCTTTTTG-3'

5'-AATTCGCCGGAGACACTCG-3'

5'-AGTGGCAAGGACACAGATGG-3'

5'-GGCTTCCGCAGCTAACACA-3'

5'-TCCTGGTACATCGAGACCTTG-3'

5'-AAGTCCCTTTCGCAGAAACAG-3'

5'-CTGCGCCGACACGATCTAC-3

5'-CGGGCCAGTCTTTTCCAGT-3'

5'-TGCTTGGACTACATCCCACAC-3'

5'-TGCAGTCTAGGAAGTTGACCA-3'

5'-ATGCTCAATCCAGAGGGAGG-3'

5'-ACTCGCAGGCCACTTAGAAAA-3'

5'-CTGGGGGAACCTGTCCTATG-3'

5'-TCATTCTGAACGCGCATGAAG-3'

5'-CTGCCGTCCAAATTCAAGAAGT-3'

5'-CTTGTGCTTCCCTGTAGGCT-3'

5'-TGGCCTTCCGTGTTCCTAC-3'

5'-GAGTTGCTGTTGAAGTCGCA-3 
culture medium; Invitrogen) for 20 min at $37{ }^{\circ} \mathrm{C}$ in a $5 \% \mathrm{CO}_{2}$ atmosphere. Samples were rinsed twice with PBS. Cell nuclei were stained with Hoechst 33342 for 10 min. TMRE staining was visualized in living cochlear explants using a confocal laser microscope.

FM 1-43 uptake. Cochlear explants were removed from the culture medium and briefly washed in PBS, then incubated in FM 1-43FX ( $5 \mu \mathrm{g} / \mathrm{ml}$ in ice-cold PBS; Invitrogen) for $30 \mathrm{~s}$. Samples were rinsed twice with PBS and fixed. After counterstaining with DAPI, FM 1-43 staining was visualized using a confocal laser microscope.

Western blotting analysis. Fifteen cochlear explants of each experimental group were lysed using an ultrasonic vibrator in $150 \mu \mathrm{l}$ ice-cold Western Lysis Buffer (Beyotime, Nantong, China) for total protein extraction. Approximately $30 \mu \mathrm{g}$ of total protein were fractionated by $8 \%$ SDS-PAGE and transferred to a PVDF membrane (Millipore, Billerica, MA, USA). Target protein was probed with primary antibodies overnight at $4{ }^{\circ} \mathrm{C}$. The primary antibodies were as follows: rabbit monoclonal anti-Bax (1:1000) (Cell Signaling Technology); rabbit monoclonal anti-caspase 9 (1:1000) (Cell Signaling Technology); rabbit monoclonal anticaspase 8 (1:1000) (Cell Signaling Technology); rabbit anti-FOX01 (1:1000) (Cell Signaling Technology); rabbit anti-FOXO3a (1:1000) (Cell Signaling Technology); and rabbit anti-GAPDH (1:5000) (Cell Signaling Technology). HRP-conjugated antirabbit IgG was used as the secondary antibody (1:5000) (Cell Signaling Technology). Bands were visualized using the ECL kit according to the manufacturer's instructions (Pierce, Thermo Scientific).

Ago2 immunoprecipitation. Fifteen explants from each experimental group were lysed using an ultrasonic vibrator in $500 \mu \mathrm{l}$ ice-cold RIP lysis buffer $(300 \mathrm{mM}$ $\mathrm{NaCl}, 5 \mathrm{mM} \mathrm{MgCl}, 0.1 \% \mathrm{NP}-40$ and $50 \mathrm{mM}$ Tris $\mathrm{HCl}, \mathrm{pH}$ 7.5, $1 \mathrm{mM}$ dithiothreitol, $1 \mathrm{mM}$ PMSF, 100 units/ml RNasin (Promega), and protease inhibitor cocktail (Roche, Basel, Switzerland) on ice). The lysate was centrifuged at $14000 \times \mathrm{g}$ at $4{ }^{\circ} \mathrm{C}$ for $10 \mathrm{~min}$. A volume of $10 \mu \mathrm{l}$ rabbit monoclonal anti-Ago2 antibody (Cell Signaling Technology) or $10 \mu \mathrm{g}$ normal rabbit IgG (Santa Cruz Biotechnology, Dallas, TX, USA) were added to the supernatant and gently rotated overnight at $4{ }^{\circ} \mathrm{C}$. Protein A Beads slurry ( $50 \mu$; Santa Cruz Biotechnology) was added and incubated for $3 \mathrm{~h}$ at $4{ }^{\circ} \mathrm{C}$ with gentle rotation. Beads were pelleted at 2500 r.p.m. for $5 \mathrm{~min}$, the supernatant was removed, and beads were washed three times in $1 \mathrm{ml}$ ice-cold wash buffer ( $150 \mathrm{mM} \mathrm{NaCl}, 1 \mathrm{mM} \mathrm{MgCl}, 0.05 \% \mathrm{NP}-40$, and $50 \mathrm{mM}$ Tris $\mathrm{HCl}$; (pH 7.5)) for $10 \mathrm{~min}$ each. The wash buffer was decanted, and bound material was eluted from beads with $50 \mu \mathrm{l}$ of $0.1 \mathrm{M}$ glycine $(\mathrm{pH} 2.3)$ for $10 \mathrm{~min}$ at room temperature. Eluted fractions were neutralized immediately with an equal volume of $1 \mathrm{M}$ Tris- $\mathrm{HCl}(\mathrm{pH} 8)$ and then treated with $20 \mathrm{U}$ of proteinase $\mathrm{K}$ for $10 \mathrm{~min}$ at $55^{\circ} \mathrm{C}$. Co-precipitated RNA was extracted using TRIzol reagent (Invitrogen). RNA (100 ng) was then subjected to miRNA and mRNA quantification.

Statistical analysis. All experiments were performed independently in triplicate. All data are shown as means \pm S.E.M. Student's t-test and one-way ANOVA with a Newman-Keuls test were used to determine the significance of differences between two experimental groups or differences among more than two groups. Values of $P<0.05$ were considered to indicate statistical significance.

\section{Conflict of Interest}

The authors declare no conflict of interest.

Acknowledgements. This work was supported by grants from the Major State Basic Research Development Program of China (973 Program) (2011CB504500), the National Natural Science Foundation of China (No. 81230019, 81470687, and 81300825), the Construction Program of Shanghai Committee of Science and Technology (Grants 12DZ2251700 and 14DJ1400203), the Major Program of Shanghai Committee of Science and Technology (Grant 11441901000), and the Programme for Leading Medical Personnel in Shanghai.

1. Lebwohl D, Canetta R. Clinical development of platinum complexes in cancer therapy: an historical perspective and an update. Eur J Cancer 1998; 34: 1522-1534.

2. Wang D, Lippard SJ. Cellular processing of platinum anticancer drugs. Nat Rev Drug Discov 2005; 4: 307-320
3. Zsiros J, Brugieres L, Brock P, Roebuck D, Maibach R, Zimmermann A et al. Dose-dense cisplatin-based chemotherapy and surgery for children with high-risk hepatoblastoma (SIOPEL-4): a prospective, single-arm, feasibility study. Lancet Oncol 2013; 14: 834-842.

4. D'Addario G, Pintilie M, Leighl NB, Feld R, Cerny T, Shepherd FA. Platinum-based versus non-platinum-based chemotherapy in advanced non-small-cell lung cancer: a meta-analysis of the published literature. J Clin Oncol 2005; 23: 2926-2936.

5. Rossi A, Di Maio M, Chiodini P, Rudd RM, Okamoto H, Skarlos DV et al. Carboplatin- or cisplatin-based chemotherapy in first-line treatment of small-cell lung cancer: the COCIS meta-analysis of individual patient data. J Clin Oncol 2012; 30: 1692-1698.

6. Brock PR, Knight KR, Freyer DR, Campbell KC, Steyger PS, Blakley BW et al. Platinuminduced ototoxicity in children: a consensus review on mechanisms, predisposition, and protection, including a New International Society of Pediatric Oncology Boston Ototoxicity Scale. J Clin Oncol 2012: 30: 2408-2417.

7. Gonzalez VM, Fuertes MA, Alonso C, Perez JM. Is cisplatin-induced cell death always produced by apoptosis? Mol Pharmacol 2001; 59: 657-663.

8. Jamieson ER, Lippard SJ. Structure, recognition, and processing of cisplatin-DNA adducts. Chem Rev 1999; 99: 2467-2498.

9. Alam SA, Ikeda K, Oshima T, Suzuki M, Kawase T, Kikuchi T et al. Cisplatin-induced apoptotic cell death in Mongolian gerbil cochlea. Hear Res 2000; 141: 28-38.

10. van Ruijven MWM, de Groot JC, Klis SF, Smoorenburg GF. The cochlear targets of cisplatin: an electrophysiological and morphological time-sequence study. Hear Res 2005; 205: 241-248.

11. Hill GW, Morest DK, Parham K. Cisplatin-induced ototoxicity: effect of intratympanic dexamethasone injections. Otol Neurotol 2008; 29: 1005-1011.

12. Waissbluth S, Pitaro J, Daniel SJ. Gene therapy for cisplatin-induced ototoxicity: a systematic review of in vitro and experimental animal studies. Otol Neurotol 2012; 33: 302-310.

13. Bartel DP. MicroRNAs: genomics, biogenesis, mechanism, and function. Cell 2004; 116 281-297.

14. Brodersen $P$, Voinnet $O$. Revisiting the principles of microRNA target recognition and mode of action. Nat Rev Mol Cell Biol 2009; 10: 141-148.

15. Pierce ML, Weston MD, Fritzsch B, Gabel HW, Ruvkun G, Soukup GA. MicroRNA-183 family conservation and ciliated neurosensory organ expression. Evol Dev 2008; 10: 106-113.

16. Wienholds E, Kloosterman WP, Miska E, Alvarez-Saavedra E, Berezikov E, de Bruijn E et al. MicroRNA expression in zebrafish embryonic development. Science 2005; 309: 310-311.

17. Weston MD, Pierce ML, Rocha-Sanchez S, Beisel KW, Soukup GA. MicroRNA gene expression in the mouse inner ear. Brain Res 2006; 1111: 95-104.

18. Sacheli R, Nguyen L, Borgs L, Vandenbosch R, Bodson M, Lefebvre $P$ et al. Expression patterns of miR-96, miR-182 and miR-183 in the development inner ear. Gene Expr Patterns 2009; 9: 364-370.

19. Li H, Kloosterman W, Fekete DM. MicroRNA-183 family members regulate sensorineural fates in the inner ear. J Neurosci 2010; 30: 3254-3263.

20. Friedman LM, Dror AA, Mor E, Tenne T, Toren G, Satoh T et al. MicroRNAs are essential for development and function of inner ear hair cells in vertebrates. Proc Natl Acad Sci USA 2009; 106: 7915-7920.

21. Fendler A, Jung M, Stephan C, Erbersdobler A, Jung K, Yousef GM. The antiapoptotic function of miR-96 in prostate cancer by inhibition of FOXO1. PLOS One 2013; 8: e80807.

22. Li J, Fu H, Xu C, Tie Y, Xing R, Zhu J et al. miR-183 inhibits TGF-beta1-induced apoptosis by downregulation of PDCD4 expression in human hepatocellular carcinoma cells. BMC Cance 2010; 10: 354.

23. Shi Y. Caspase activation: revisiting the induced proximity model. Cell 2004; 117: 855-858.

24. Atar O, Avraham KB. Anti-apoptotic factor Z-Val-Ala-Asp-fluoromethylketone promotes the survival of cochlear hair cells in a mouse model for human deafness. Neuroscience 2010; 168: 851-857.

25. Green DR. Apoptotic pathways: the roads to ruin. Cell 1998; 94: 695-698.

26. Galluzzi L, Zamzami N, de La Motte Rouge T, Lemaire C, Brenner C, Kroemer G. Methods for the assessment of mitochondrial membrane permeabilization in apoptosis. Apoptosis 2007; 12: 803-813.

27. Thomas AJ, Hailey DW, Stawicki TM, Wu P, Coffin AB, Rubel EW et al. Functional mechanotransduction is required for cisplatin-induced hair cell death in the zebrafish lateral line. J Neurosci 2013; 33: 4405-4414.

28. Segura MF, Hanniford D, Menendez S, Reavie L, Zou X, Alvarez-Diaz S et al. Aberrant miR-182 expression promotes melanoma metastasis by repressing FOXO3 and microphthalmia-associated transcription factor. Proc Natl Acad Sci USA 2009; 106 $1814-1819$

29. Moskwa P, Buffa FM, Pan Y, Panchakshari R, Gottipati P, Muschel RJ et al. miR-182 mediated downregulation of BRCA1 impacts DNA repair and sensitivity to PARP inhibitors. Mol Cell 2011; 41: 210-220.

30. Guttilla IK, White BA. Coordinate regulation of FOXO1 by miR-27a, miR-96, and miR-182 in breast cancer cells. J Biol Chem 2009; 284: 23204-23216.

31. Myatt SS, Wang J, Monteiro LJ, Christian M, Ho KK, Fusi L et al. Definition of microRNAs that repress expression of the tumor suppressor gene FOXO1 in endometrial cancer. Cancer Res 2009; 70: 367-377.

32. Huang H, Tindall DJ. Dynamic FoxO transcription factors. J Cell Sci 2007; 120(Pt 15): 2479-2487. 
33. Meister G. Argonaute proteins: functional insights and emerging roles. Nat Rev Genet 2013; 14: 447-459.

34. Kuhn CD, Joshua-Tor L. Eukaryotic Argonautes come into focus. Trends Biochem Sci 2013; 38: 263-271.

35. Tzivion G, Dobson M, Ramakrishnan G. FoxO transcription factors; regulation by AKT and 14-3-3 proteins. Biochim Biophys Acta 2011; 1813: 1938-1945.

36. Burgering BM, Kops GJ. Cell cycle and death control: long live Forkheads. Trends Biochem Sci 2002; 27: 352-360.

37. Chung WH, Pak K, Lin B, Webster N, Ryan AF. A PI3K pathway mediates hair cell survival and opposes gentamicin toxicity in neonatal rat organ of Corti. $J$ Assoc Res Otolaryngol 2006; 7: 373-382.

38. Kelland $\mathrm{L}$. The resurgence of platinum-based cancer chemotherapy. Nat Rev Cancer 2007; 7: $573-584$.

39. Joo MS, Lee CG, Koo JH, Kim SG. miR-125b transcriptionally increased by Nrf2 inhibits AhR repressor, which protects kidney from cisplatin-induced injury. Cell Death Dis 2013; 4: e899.

40. Ouyang YB, Xu L, Lu Y, Sun X, Yue S, Xiong XX et al. Astrocyte-enriched miR-29a targets PUMA and reduces neuronal vulnerability to forebrain ischemia. Glia 2013; 61: 1784-1794.

41. Nguyen T, Rich A, Dahl R. MiR-24 promotes the survival of hematopoietic cells. Plos One 2013; 8 : 1.

42. Tan PX, Du SS, Ren C, Yao QW, Zheng R, Li R et al. MicroRNA-207 enhances radiationinduced apoptosis by directly targeting Akt3 in cochlea hair cells. Cell Death Dis 2014; 5 e1433.

43. Xiong H, Pang J, Yang H, Dai M, Liu Y, Ou Y et al. Activation of miR-34a/SIRT1/p53 signaling contributes to cochlear hair cell apoptosis: implications for age-related hearing loss. Neurobiol Aging 2015; 36: 1692-1701.

44. Zhang Q, Liu H, McGee J, Walsh EJ, Soukup GA, He DZ. Identifying microRNAs involved in degeneration of the organ of corti during age-related hearing loss. PLOS One 2013; 8: e62786.

45. Kuhn S, Johnson SL, Furness DN, Chen J, Ingham N, Hilton JM et al. miR-96 regulates the progression of differentiation in mammalian cochlear inner and outer hair cells. Proc Nat Acad Sci USA 2011; 108: 2355-2360.

46. Lewis MA, Quint E, Glazier AM, Fuchs H, De Angelis MH, Langford C et al. An ENU-induced mutation of miR-96 associated with progressive hearing loss in mice. Nat Genet 2009; 41: 614-618.

47. Mencia A, Modamio-Høybjør S, Redshaw N, Morín M, Mayo-Merino F, Olavarrieta L et al. Mutations in the seed region of human miR-96 are responsible for nonsyndromic progressive hearing loss. Nat Genet 2009; 41: 609-613.

48. Yu S, Lu Z, Liu C, Meng Y, Ma Y, Zhao W et al. miRNA-96 suppresses KRAS and functions as a tumor suppressor gene in pancreatic cancer. Cancer Res 2010; 70: 6015-6025.

49. Li C, Du X, Tai S, Zhong X, Wang Z, Hu Z et al. GPC1 regulated by miR-96-5p, rather than miR-182-5p, in inhibition of pancreatic carcinoma cell proliferation. Int J Mol Sci 2014 15: 6314-6327.

50. Sirotkin AV, Lauková M, Ovcharenko D, Brenaut $P$, Mlyncek M. Identification of microRNAs controlling human ovarian cell proliferation and apoptosis. J Cell Physiol 2010; 223: 49-56.

51. Lumayag S, Haldin CE, Corbett NJ, Wahlin KJ, Cowan C, Turturro S et al. Inactivation of the microRNA-183/96/182 cluster results in syndromic retinal degeneration. Proc Natl Acad Sci USA 2013; 110: E507-E516.

52. Bartel DP. MicroRNAs: target recognition and regulatory functions. Cell 2009; 136: 215-233.
53. Hartl M, Grunwald Kadow IC. New roles for "old" microRNAs in nervous system function and disease. Front Mol Neurosci 2013; 6: 51.

54. Rudnicki A, Avraham KB. microRNAs: the art of silencing in the ear. EMBO Mol Med 2012; 4: 849-859.

55. Newmeyer DD, Ferguson-Miller S. Mitochondria: releasing power for life and unleashing the machineries of death. Cell 2003; 112: 481-490.

56. Cecconi F. Apaf1 and the apoptotic machinery. Cell Death Differ 1999; 6: 1087-1098.

57. Langer T, am Zehnhoff-Dinnesen A, Radtke S, Meitert J, Zolk O. Understanding platinuminduced ototoxicity. Trends Pharmacol Sci 2013; 34: 458-469.

58. Waissbluth S, Daniel SJ. Cisplatin-induced ototoxicity: transporters playing a role in cisplatin toxicity. Hear Res 2013; 299: 37-45.

59. More SS, Akil O, lanculescu AG, Geier EG, Lustig LR, Giacomini KM. Role of the copper transporter, CTR1, in platinum-induced ototoxicity. J Neurosci 2010; 30: 9500-9509.

60. Sunters A, Fernández de Mattos S, Stahl M, Brosens JJ, Zoumpoulidou G, Saunders CA et al. FoxO3a transcriptional regulation of Bim controls apoptosis in paclitaxel-treated breast cancer cell lines. J Biol Chem 2003; 278: 49795-49805.

61. Essafi A, Fernández de Mattos S, Hassen YA, Soeiro I, Mufti GJ, Thomas NS et al. Direct transcriptional regulation of Bim by FoxO3a mediates STI571-induced apoptosis in Bcr-Abl-expressing cells. Oncogene 2005; 24: 2317-2329.

62. Czabotar PE, Colman PM, Huang DC. Bax activation by Bim? Cell Death Differ 2009; 16 : 1187-1191.

63. $\mathrm{Yu} \mathrm{H}$, Lin $\mathrm{Q}$, Wang $\mathrm{Y}, \mathrm{He} \mathrm{Y}$, Fu S, Jiang $\mathrm{H}$ et al. Inhibition of $\mathrm{H} 3 \mathrm{~K} 9$ methyltransferases G9a/GLP prevents ototoxicity and ongoing hair cell death. Cell Death Dis 2013; 4: e506.

64. He Y, Yu H, Cai C, Sun S, Chai R, Li H. Inhibition of H3K4me2 demethylation protects auditory hair cells from neomycin-induced apoptosis. Mol Neurobiol 2014; 52: $196-205$.

65. Shi R, Chiang V. Facile means for quantifying microRNA expression by real-time PCR. BioTechniques 2005; 39: 519-525.

66. Zhang J, Du YY, Lin YF, Chen YT, Yang L, Wang HJ et al. The cell growth suppressor, mir-126, targets IRS-1. Biochem Biophys Res Commun 2008; 377: 136-140.

67. Livak KJ, Schmittgen TD. Analysis of relative gene expression data using real-time quantitative PCR and the 2(-Delta Delta C(T)) method. Methods 2001; 25: 402-408.

(c) Cell Death and Disease is an open-access journal published by Nature Publishing Group. This work is licensed under a Creative Commons Attribution 4.0 International License. The images or other third party material in this article are included in the article's Creative Commons license, unless indicated otherwise in the credit line; if the material is not included under the Creative Commons license, users will need to obtain permission from the license holder to reproduce the material. To view a copy of this license, visit http://creativecommons.org/licenses/by/4.0/

(C) The Author(s) 2016

Supplementary Information accompanies this paper on Cell Death and Disease website (http://www.nature.com/cddis) 